\title{
ANÁLISIS SOBRE LA INFLUENCIA DE LA PERCEPCIÓN DEL RIESGO SÍSMICO EN EL DESARROLLO DE LOS PLANES INSTITUCIONALES DE GESTIÓN PARA LA REDUCCIÓN DEL RIESGO: EL CASO DEL CANTÓN DE NICOYA Y EL CANTÓN CENTRAL DE PUNTARENAS
}

\author{
Alexander Solís Delgado (2009)
}

Con base en las investigaciones sobre amenaza sísmica en el segmento de la Península de Nicoya, se estudió la percepción del riesgo por parte de los representantes institucionales vinculados a la organización local del riesgo en el cantón de Nicoya y cantón Central de Puntarenas.

El estudio incluye la relación entre lo que manifiestan los y las representantes de las organizaciones responsables de la gestión para la redacción del riesgo a desastres en los cantones de referencia y la realidad de la preparación de las instituciones en términos de disponibilidad de presupuesto, participación en las estructuras de coordinación, disponibilidad y pertinencia de ios planes de preparativos y respuesta.
La revisión e integración de información técnica sobre la amenaza sísmica, relacionada con los abordajes periodísticos y la divulgación realizada por las instituciones, permitió identificar las brechas que originan la inadecuada preparación para enfrentar los efectos de un evento sísmico.

La propuesta de organización para la reducción del riesgo acorde con la legislación nacional y los enfoques propuestos para la comunicación del riesgo, permitirán a la Comisión Nacional de Prevención de Riesgos y Atención de Emergencias (CNE) abordar en forma coordinada y eficiente los planes para la reducción del riesgo por sismo en el cantón de Nicoya y cantón Central de Puntarenas. 